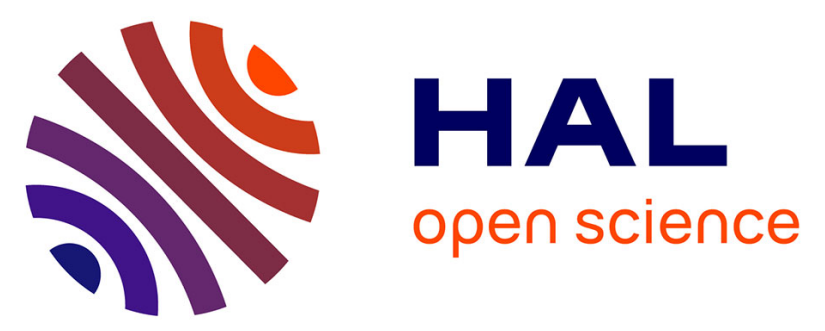

\title{
Cineole-containing nanoemulsion: Development, stability, and antibacterial activity
}

\author{
Tayonara Lima, Maria Fátima S. Silva, Xirley Nunes, Andrea Colombo, \\ Helinando Oliveira, Patrícia Goto, Henrique Piva, Antonio Tedesco, \\ Marigilson Siqueira-Moura, Muriel Blanzat
}

\section{To cite this version:}

Tayonara Lima, Maria Fátima S. Silva, Xirley Nunes, Andrea Colombo, Helinando Oliveira, et al.. Cineole-containing nanoemulsion: Development, stability, and antibacterial activity. Chemistry and Physics of Lipids, 2021, 239, pp.105113. 10.1016/j.chemphyslip.2021.105113 hal-03341888

\section{HAL Id: hal-03341888 \\ https://hal.science/hal-03341888}

Submitted on 18 Oct 2021

HAL is a multi-disciplinary open access archive for the deposit and dissemination of scientific research documents, whether they are published or not. The documents may come from teaching and research institutions in France or abroad, or from public or private research centers.
L'archive ouverte pluridisciplinaire HAL, est destinée au dépôt et à la diffusion de documents scientifiques de niveau recherche, publiés ou non, émanant des établissements d'enseignement et de recherche français ou étrangers, des laboratoires publics ou privés. 
1 Cineole-containing nanoemulsion: development, stability, and antibacterial activity

2

3 Tayonara S. Lima ${ }^{a}$, Maria Fátima S. Silva ${ }^{a}$, Xirley P. Nunes ${ }^{a, b}$, Andrea V. Colombo ${ }^{a, b}$,

4 Helinando P. Oliveira ${ }^{\mathrm{c}}$, Patrícia L. Goto ${ }^{\mathrm{d}}$, Muriel Blanzat ${ }^{\mathrm{d}}$, Henrique L. Piva ${ }^{\mathrm{e}}$, Antonio C.

$5 \quad$ Tedesco $^{\mathrm{e}}$, Marigilson P. Siqueira-Moura ${ }^{\mathrm{a}, \mathrm{b}}$

6

7 a Graduate Program in Biosciences (PPGB), Federal University of the São Francisco

$8 \quad$ Valley (UNIVASF), Petrolina, Pernambuco 56304-205, Brazil

9 bollege of Pharmaceutical Sciences (CFARM), Federal University of the São Francisco

10 Valley (UNIVASF), Petrolina, Pernambuco 56304-205, Brazil

$11{ }^{\mathrm{c}}$ Graduate Program in Materials Science (PPGCM), Federal University of the São

12 Francisco Valley (UNIVASF), Juazeiro, Bahia 48902-300, Brazil

13 dMRCP Laboratory, UMR 5623 CNRS, Paul Sabatier University, 31062 Toulouse,

14 France

eDepartment of Chemistry, Center of Nanotechnology and Tissue Engineering -

Photobiology and Photomedicine Research Group, Faculty of Philosophy, Sciences and

Letters of Ribeirão Preto (FFCLRP), University of São Paulo (USP), Ribeirão Preto, São

Paulo 14040-901, Brazil

19

*Corresponding author:

Prof. Marigilson Pontes de Siqueira Moura, Ph.D.

College of Pharmaceutical Sciences - UNIVASF

Prédio dos Colegiados, Av. José de Sá Maniçoba, S/N, 56304-917, Centro, Petrolina-PE, 
Abstract

1,8-cineole is a monoterpene commonly used by the food, cosmetic, and pharmaceutical industries owing to its flavor and fragrances properties. In addition, this bioactive monoterpene has demonstrated bactericidal and fungicidal activities. However, such activities are limited due to its low aqueous solubility and stability. This study aimed to develop nanoemulsion containing cineole and assess its stability and antibacterial activity in this context. The spontaneous emulsification method was used to prepare nanoemulsion (NE) formulations (F1, F2, F3, F4, and F5). Following the development of NE formulations, we chose the F1 formulation that presented an average droplet size (in diameter) of about $100 \mathrm{~nm}$ with narrow size distribution $(\mathrm{PdI}<0.2)$ and negative zeta potential $(\sim-35 \mathrm{mV})$. According to the analytical centrifugation method with photometric detection, F1 and F5 formulations were considered the most stable NE with lower droplet migration velocities. In addition, F1 formulation showed high incorporation efficiency (> $80 \%$ ) and TEM analyses demonstrated nanosized oil droplets with irregular spherical shapes and without any aggregation tendency. Antibacterial activity assessment showed that F1 NE was able to enhance the cineole action against Staphylococcus aureus, Enterococcus faecalis, and Streptococcus pyogenes. Therefore, using a simple and reproducible method of low energy emulsification we designed a stable nanoemulsion containing 1,8-cineole with improved antibacterial activity against Gram-positive strains.

Keywords: 1,8-cineole, Spontaneous emulsification, Nanoemulsion, Stability, Antibacterial activity. 


\section{Introduction}

In nature, bioactive oils based on terpene (isoprene) and terpenoid compounds are synthesized by aromatic plants as secondary metabolites, commonly known as essential oils (EO) or volatile oils. Monoterpenes are formed by two isoprene units (10 carbon atoms) and constitute more than $80 \%$ of EO composition (Asbahani et al., 2015; Bakkali et al., 2008; Bilia et al., 2014; Matos et al., 2019; Slamenova and Horvathova, 2013). According to each plant source, EO comprise widely varied monoterpenes, sesquiterpenes, and phenylpropenes combinations. There is a terpenic oxide among such monoterpenes, namely 1,8 -cineole $\left(\mathrm{C}_{10} \mathrm{H}_{18} \mathrm{O}\right.$; M.W. $\left.154.25 \mathrm{~g} \mathrm{~mol}^{-1}\right)$, which is a cyclic ether found as the main constituent in EO obtained from eucalyptus species. This monoterpene is a limpid and colorless oily liquid with a strong camphor-like odor and also called 1,8-epoxy-p-menthane, eucalyptol, and cajeputol (Adak et al., 2020; Ali et al., 2015; De Vincenzi et al., 2002; Salehi et al., 2019; Slamenova and Horvathova, 2013).

Owing to its bactericidal and fungicidal activities as well as flavor and fragrances properties, 1,8-cineole has been used by food, cosmetic, and pharmaceutical industries. However, despite all these applications, the use of 1,8-cineole or EO containing this terpene is limited due to its limited thermal stability, substantial volatility, and low water solubility (Adak et al., 2020; Hammoud et al., 2019; Prakash et al., 2018a; Prakash et al., 2018b).

In order to prevent terpenes and phenylpropanoid derivatives volatilization or oxidation, as well as their degradation by light and for improving the chemical stability, the encapsulation of these compounds into nanostructured systems has been commonly used. Several nanocarriers have been well designed to entrap EO or their main compounds in this context. Among these carriers, the choice covers polymeric nanocapsules or nanoparticles, liposomes, phytosomes, nanoemulsions, microemulsions, solid lipid 
nanoparticles, and nanostructured lipid carriers (Asbahani et al., 2015; Bilia et al., 2014; Harwansh et al., 2019; Matos et al., 2019; Prakash et al. 2018a; Prakash et al., 2018b; Zhao et al., 2016).

Oil-in-water nanoemulsion is the most often-used colloidal lipid carrier to incorporate EO. According to recent review conducted by Matos et al. (2019), almost half of all nanostructured systems containing EO was represented by nanoemulsified dispersions. Nanoemulsions (NE) are ultrafine dispersions constituted of two immiscible liquids (organic and aqueous phases) stabilized by surfactant(s). Despite being considered nonequilibrium systems (thermodynamically unstable), nanoemulsions are metastable or kinetically stable colloidal dispersions (Anton and Vandamme, 2011; Gupta et al., 2016; Helgeson, 2016; Komaiko and McClements, 2016; Singh et al., 2017; Solans and Solé, 2012).

In general, nanoemulsions are produced using low or high-energy methods. High-energy emulsification approaches, i.e., work-based emulsification methods, usually require sophisticated and expensive devices, namely high-pressure homogenizers, ultrasound generators, and microfluidizers. On the other hand, low-energy methods or thermodynamic methods are easy production processes based on simple stirring and changing some formulation parameters, e.g., surfactant concentration and type, oil-water ratio, temperature, etc. Usually low-energy emulsification methods have been categorized as phase inversion composition, phase inversion temperature, emulsion inversion point, and spontaneous emulsification (Anton and Vandamme, 2009; Gupta et al., 2016; Helgeson, 2016; Komaiko and McClements, 2016; Safaya and Rotliwala, 2020; Singh et al., 2017; Solans and Solé, 2012).

The main reason for incorporating EO or their major constituents into the lipid core of nanoemulsion is directly related to bioactive molecules improving their stability and 
subsequent enhanced bioefficacy (Asbahani et al., 2015; Bilia et al., 2014; Harwansh et al., 2019; Matos et al., 2019). Also, EO-based nanoemulsion formulations have received increasing attention as effective nanocarriers improving antimicrobial activity of bioactive components (Prakash et al., 2018a; Prakash et al., 2018b). Nevertheless, available information about preparation, stability, and biological activities of nanoemulsions containing isolated bioactive compounds from EO is still scarce, requiring more investigations. Therefore, this study aimed to develop cineole-containing nanoemulsion formulation using an isothermal low-energy emulsification method and assess its accelerated stability and antibacterial activity.

\section{Materials and methods}

\subsection{Materials}

1,8-Cineole (Eucalyptol $99 \%, \mathrm{~d}=0.921 \mathrm{~g} \mathrm{~mL}^{-1}$ at $25{ }^{\circ} \mathrm{C}$ ), sorbitan monooleate (SMO), polyoxyethylen-20 sorbitan monolaurate (SML-20), polyoxyethylen-20 sorbitan monooleate (SMO-20), sodium phosphate monobasic, and sodium phosphate dibasic were purchased from Sigma-Aldrich Co. (St. Louis, MO, USA). Medium-chain triglycerides (MCT, $\mathrm{d}=0.94 \mathrm{~g} \mathrm{~mL}^{-1}$ at $20{ }^{\circ} \mathrm{C}$ ) oil was kindly supplied from Brasquim (Porto Alegre-RS, Brazil).

\subsection{Nanoemulsion preparation}

Nanoemulsions (NE) were prepared using a method based on a spontaneous emulsification procedure described by Saberi et al. (2014) with slight modifications. Briefly, spontaneous emulsification was carried out by addition of an organic phase consisting of carrier oil (MCT), 1,8-cineole, and surfactant(s), to an aqueous phase 
126 (phosphate buffer solution $\mathrm{pH}$ 7.4) under magnetic stirring (200 rpm) and ambient

127 temperature kept constant throughout process. Initially, different ratios between phases

128 and surfactant mixtures were assessed to find more suitable formulations resulting in final

129 composition (wt. \%) of the five nanoemulsions reported in Table 1. Thus, both carrier oil-

130 to-cineole and surfactant-to-oil weight ratios were kept constant at 1.0 and 2.0,

131 respectively. The proportion of surfactant:oil:water was set at 10:10:80 (wt. \%),

132 respectively, and for $\mathrm{F} 1, \mathrm{~F} 3$, and F5 formulations the surfactant combinations were

133 maintained at HLB 12 (Table 1). All formulations were prepared three times $(\mathrm{n}=15)$ and

134 stored at $4{ }^{\circ} \mathrm{C}( \pm 2)$. Unloaded NE (F5 formulation) was obtained from organic phase

135 composed only of carrier oil (MCT) and surfactants using the same spontaneous

136 emulsification process.

137

138

Table 1.

139

Composition (wt. \%) of NE formulations.

\begin{tabular}{lllllll}
\hline NE & SML-20 & SMO-20 & SMO & MCT & Cin & PBS \\
\hline F 1 & 6.2 & - & 3.8 & 5.0 & 5.0 & 80 \\
F 2 & 10 & - & - & 5.0 & 5.0 & 80 \\
F 3 & - & 7.2 & 2.8 & 5.0 & 5.0 & 80 \\
F 4 & - & 10 & - & 5.0 & 5.0 & 80 \\
F 5 & 6.2 & - & 3.8 & 10 & - & 80
\end{tabular}

SML-20: polyoxyethylen-20 sorbitan monolaurate; SMO-20: polyoxyethylen-20 sorbitan monooleate; SMO: sorbitan monooleate; MCT: medium-chain triglycerides; Cin: 1,8cineole; PBS: $10 \mathrm{mM}$ phosphate buffer solution pH 7.4. 
145 The hydrodynamic diameter of droplets and polydispersity index (PdI) of the NE 146 formulations were determined by photon correlation spectroscopy (PCS) at $25{ }^{\circ} \mathrm{C}$ and a 147 scattering angle of $173^{\circ}$ (Zetasizer ${ }^{\circledR}$ Nano ZS, Malvern PCS Instruments, UK). All samples were diluted (1/100) with ultra-purified water. The reported values are average \pm SEM of three different batches of each colloidal dispersion.

\subsection{Zeta potential measurement}

Zeta $(\zeta)$ potential of NE was measured by electrophoretic mobility using a Zetasizer ${ }^{\circledR}$ Nano ZS apparatus (Malvern PCS Instruments, UK). The Smoluchowski model was used to estimate $\zeta$ potential from electrophoretic mobility. The analyses were conducted at 25 ${ }^{\circ} \mathrm{C}$, and the samples were appropriately diluted (1/100) with ultra-purified water. Values reported are average \pm SEM of three different batches of each colloidal dispersion.

\subsection{Forced stability study}

Stability study was performed using the analytical centrifugation method with photometric detection at $865 \mathrm{~nm}$ (LUMiSizer ${ }^{\circledR}$ 611, LUM GmbH, Germany). The samples of NE formulations were incorporated into polycarbonate cell and equilibrated to $25{ }^{\circ} \mathrm{C}$ before analyses. Measurements were carried out at 3,618 rpm for $4.5 \mathrm{~h}$ resulting in accelerated migration of the droplets and integration of transmission profiles within a selected region of the holding cell allowed to get information about dispersion stability. The analyses were carried out using specific cuvettes with a radius position of $129.5 \mathrm{~mm}$ and based on results, it was possible to predict the shelf life of the NE samples from following equation (1) (Goto et al., 2017): 


\subsection{Incorporation efficiency}

171 1,8-cineole was determined using a UV spectrophotometric method described by Yin et al. (2021), with slight modifications. Calibration curves were constructed for 1,8-cineole in n-hexane at different concentrations (w/v) and their absorbances detected at $250 \mathrm{~nm}$ using an Even UV/VIS spectrophotometer (Ionlab, Paraná, Brazil). Total monoterpene amount in the F1 formulation was assessed with the addition of an aliquot of the formulation in n-hexane $(1: 3, \mathrm{v} / \mathrm{v})$. This mixture was put in an ultrasonic bath at $30{ }^{\circ} \mathrm{C}$ for $30 \mathrm{~min}$, and then centrifuged at 4,000 rpm for $20 \mathrm{~min}$. Next, the amount of 1,8-cineole was determined in the upper phase using UV spectrophotometric method as mentioned above. Free 1,8-cineole amount was determined by measuring the non-incorporated monoterpene present in a clear ultrafiltrate obtained through separation of aqueous phase using an ultrafiltration/ultracentrifugation procedure (Microcon Ultracel YM-100, Millipore, Ireland) at $10,583 \mathrm{x} \mathrm{g}$ for $60 \mathrm{~min}$ at $4{ }^{\circ} \mathrm{C}$ (novatecnica, Microcentrifuge NT formulation was applied to quantify free monoterpene fraction in the dispersion medium (aqueous phase). All analyses were performed in triplicate and the incorporation efficiency (IE \%) of 1,8-cineole in F1 formulation was calculated from following equation

(2) (Rodrigues et al., 2018):

$\operatorname{IE}(\%)=($ TCin - FCin/ThCin $) \times 100$

Where, TCin is the total 1,8-cineole amount; FCin, free 1,8-cineole amount; ThCin, theoretical 1,8-cineole amount.

\subsection{Electron microscopy analysis}

NE formulation was analyzed using transmission electron microscopy (TEM) technique. 
grids and negatively stained with $1 \%(\mathrm{w} / \mathrm{v})$ sodium phosphotungstate solution; the excess sample was thoroughly removed by filter paper. After that, the samples were dried at room condition before analyses. Transmission electron micrographs of the samples were taken using a Microscope HT7700 Hitachi (Fukuoka, Japan) operated at accelerating voltage of $80 \mathrm{KV}$ and emission $12 \mu \mathrm{A}$.

\subsection{Antibacterial activity assay}

The minimal bactericidal concentration of free 1,8-cineole and cineole nanoemulsion $(\mathrm{F} 1$ formulation) were determined by microdilution techniques in Mueller-Hinton broth (MHB) (CLSI, 2018). Briefly, serial twofold dilutions of free 1,8-cineole and F1 formulation were carried out in MHB using 96-well microplates. Bacterial suspension $\left(10^{8} \mathrm{CFU} \mathrm{mL} \mathrm{mL}^{-1}\right)$ cultured in TSB at $37^{\circ} \mathrm{C}$ for $24 \mathrm{~h}$ were inoculated onto wells $(200 \mu \mathrm{L}$ final volume). Microplates were incubated at $35^{\circ} \mathrm{C}$ for $24 \mathrm{~h}$. Bacterial growth control $(\mathrm{MHB}+$ strain + DMSO $10 \%)$, sterility control $(\mathrm{MHB})$, and positive controls with gentamicin and chlorhexidine digluconate were performed simultaneously on assays. An aliquot of $10 \mu \mathrm{L}$ of each well was inoculated on Mueller-Hinton Agar (MHA) at $37{ }^{\circ} \mathrm{C}$ for $24 \mathrm{~h}$ for colonies growth. Minimal bactericidal concentration was defined as the lowest 1,8-cineole or F1 concentration that did not allow visible growth on MHA agar. Experiments were performed three times.

\subsection{Statistical analysis}

All experiments were performed three times and data are expressed as average value $( \pm$ SEM). Statistical analysis was performed by One-way ANOVA followed by Tukey’s pairwise comparisons using the Prism GraphPad Software. The statistical significance was set at $\mathrm{p}<0.05$. 


\section{Results and discussion}

222 In this study, cineole nanoemulsions were prepared using the spontaneous emulsification method as an isothermal approach applied to volatile and hydrophobic organic compounds. In order to prepare colloidal dispersions containing 1,8-cineole, as aqueous phase was used PBS ( $\mathrm{pH} 7.4$ ) while organic phase consisted of a mixture of cineole and MTC (1:1 w/w), and different types of surfactants.

For emulsions obtained herein, there was a variation of visual appearance among the fluid nanoemulsified dispersions from slightly turbid with bluish reflection to milky opaque dispersion reflecting directly the dispersed phase formed in each colloidal formulation. As shown in Table 2, the main properties of nanoemulsified systems were dependent on both surfactant types and organic phase composition. The types of nonionic surfactants used in the formulations demonstrated a considerable influence over droplet average diameter and size distribution of the colloidal dispersions. Hence, the smallest droplets $(<115 \mathrm{~nm})$ and with the narrowest size distribution (PdI $<0.2$ and monomodal) were observed for F1 formulation ( $\mathrm{p}<0.05$ ), which was prepared containing SML-20 and SMO as pair of nonionic surfactants. In contrast, the largest droplets with broader size distribution were noticed from dispersion prepared with SMO-20 and SMO surfactants (F3 formulation). Likewise, for those formulations containing only SML-20 or SMO-20 as a surfactant, i.e., F2 and F4 formulations, respectively, the droplet average sizes were higher than $150 \mathrm{~nm}$ and the droplet size distribution was bimodal with PdI values above 0.2. Moreover, when the organic phase composition was altered to contain only MCT carrier oil, the droplet average diameter and size distribution were significantly larger than other NE formulations, as can be particularly observed comparing F1 and F5 formulations $(\mathrm{p}<0.05)$. Similarly, the organic phase composition also influenced both 
droplet size e PdI of NE formulations, e.g., F5 formulation, whose organic phase consisted entirely of MCT oil presented relatively large droplets $(\mathrm{p}<0.05)$. This result is in accord with earlier research developed by Saberi et al. (2013) in which the increasing MCT oil concentrations resulted in larger droplets from mini-emulsions. Such influence might be explained by the significant impact of the MCT carrier oil on surfactant spontaneous curvature and solubility affecting directly formation of small droplets (Komaiko and McClements, 2016; Saberi et al., 2014).

The mechanism assigned to the formation of small-sized droplets using spontaneous emulsification is directly connected to the fast displacement of surfactant(s) from organic phase into aqueous phase. Afterward, both phases come into contact; this mixture results in the rapid diffusion of surfactant(s) from organic to aqueous phase producing turbulence at oil/water interface and consequent formation of fine droplets (Anton and Vandamme, 2009; Komaiko and McClements, 2016; Saberi et al., 2013). It is commonly recognized that some factors can affect the formation and stability of nanodroplets designed from spontaneous emulsification approach. Among such factors are organic phase composition, type and concentration of surfactant(s) and/or cosurfactant(s), and conditions related to emulsifying process (Helgeson, 2016; Komaiko and McClements, 2016).

Zeta $(\zeta)$ potential reflects surface charge of droplets and it has been related to stability of colloidal formulations. High surface charge density may imply NE's long-term physical stability due to relevant repulsive electrostatic forces among the droplets preventing rapid aggregation and flotation of dispersed phase (McClements and Gumus, 2016; Singh et al., 2017). All NE formulations presented significant negative values of zeta potential (< - $20 \mathrm{mV}$, Table 2) which may be related to free ionized groups from components of organic phase. It is worth mentioning that additionally electrostatic stabilization of the 
dispersed phase, the nanoemulsion physical stability is also a result of van der Waals, hydrophobic, and steric interactions among droplets (Gupta et al., 2016; Helgeson, 2016; McClements and Gumus, 2016; Singh et al., 2017).

273

Table 2.

Droplet size (hydrodynamic diameter), polydispersity index (PdI), and $\zeta$ potential of NE formulations (average \pm SEM, $\mathrm{n}=3$ ).

\begin{tabular}{llll}
\hline NE & Size $(\mathrm{nm})$ & PdI & $\zeta$ potential $(\mathrm{mV})$ \\
\hline F1 & $111.5( \pm 0.79)^{\mathrm{a}}$ & $0.182( \pm 0.007)^{\mathrm{b}}$ & $-36.75( \pm 0.33)$ \\
F2 & $203.4( \pm 6.68)$ & $0.303( \pm 0.017)$ & $-29.43( \pm 0.54)$ \\
F3 & $212.8( \pm 8.67)$ & $0.223( \pm 0.004)$ & $-38.60( \pm 0.17)$ \\
F4 & $159.3( \pm 1.28)$ & $0.240( \pm 0.015)$ & $-19.75( \pm 0.36)^{\mathrm{c}}$ \\
F5 & $264.5( \pm 1.17)$ & $0.321( \pm 0.014)$ & $-42.02( \pm 0.42)$
\end{tabular}

${ }^{\mathrm{a}} \mathrm{p}<0.05$ compared to F2, F3, F4, and F5 formulations concerning size.

${ }^{b} \mathrm{p}<0.05$ compared to F2, F3, F4, and F5 formulations concerning PdI.

${ }^{c} \mathrm{p}<0.05$ compared to F1, F2, F3, and F5 formulations concerning $\zeta$ potential.

Once nanosized oil droplets are formed, it is essential that their stability can be assessed throughout the formulation lifetime. In this study, centrifugal separation analysis with photometric detection enabled physical stability assessment of the NE formulations. The analytical photocentrifugation method is based on the measurement of droplet migration by applying a centrifugal force and photometric detection using near-infrared (NIR) light. by sensors forming profiles of light transmission as a function of time and position. The shape and gradual change process of the light transmission profiles through tested 
samples allow the analysis of separation kinetics of dispersed phase from continuous phase in colloidal dispersions enabling a comparison of long-term stability among NE formulations (Fernandes et al., 2017). For each NE sample, 255 transmission profiles were recorded in intervals of $65 \mathrm{~s}$, and flotation velocities of oil droplets from undiluted samples of the NE were determined at $25{ }^{\circ} \mathrm{C}$ (Table 3).

Fig. 1 shows NIR transmission profiles obtained for F1 and F5 formulations while Fig. 2 shows transmission profiles for F2, F3, and F4 formulations. F1 and F5 formulations presented similar transmission profiles (Fig. 1) with the lowest clarification process, i.e., minimal phase separation due to the dispersed phase's flotation. These results were confirmed by flotation velocity obtained for F1 and F5; for these two formulations, the flotation velocities were the lowest among all samples as well as a narrower velocity distribution was also observed with only slight speed variation of droplet migration between D10 \% and D90 \% as shown in Table 3. Thus, we considered that F1 and F5 were the most stable NE formulations. Moreover, this result confirms that the inclusion coating in the oil droplets preventing aggregation of the dispersed phase and consequent improvement physical stability of these formulations. Therefore, such an outcome may 

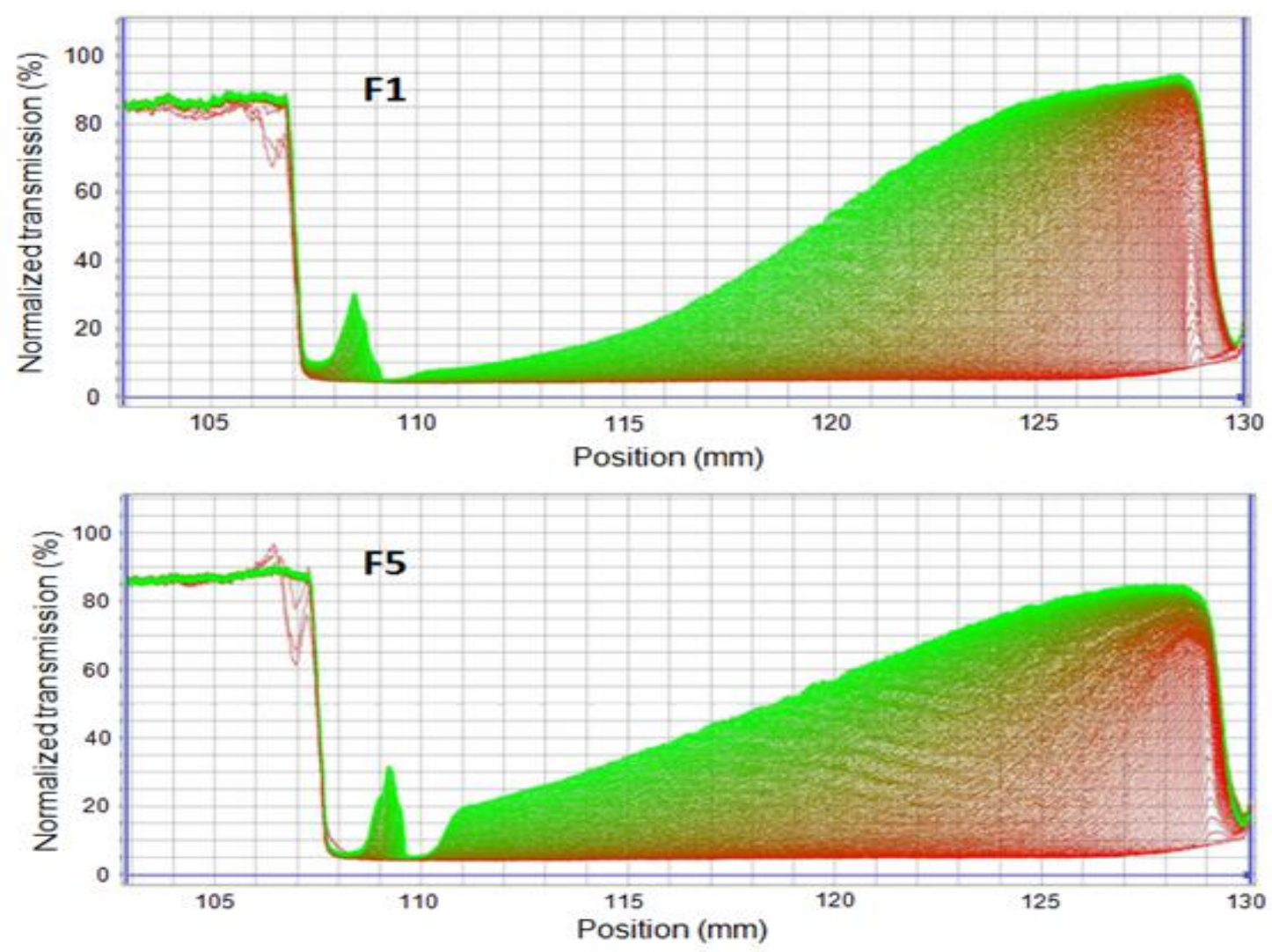

Fig. 1. Normalized NIR transmission profiles obtained with cineole-containing NE (F1) and unloaded NE (F5) formulations by accelerated stability analysis during analytical centrifugation. The first and the last registered profiles are shown in red and in green, respectively.

The main destabilization mechanisms of nanoemulsified systems are related to close contact among droplets which may result in flocculation, Ostwald ripening, coalescence, and lastly phase separation. Thus, any aggregation process of the dispersed phase may trigger such instabilities and, consequently, the coarsening of the colloidal formulations

327 (Gupta et al., 2016; Helgeson, 2016; Singh et al., 2017). In this study, it seems reasonable to assume that the adsorbed layer of SML-20 and SMO surfactants on the oil droplets 
increased the steric stabilization of F1 and F5 formulations avoiding oil droplet aggregation. It is also important to note that the addition of MCT carrier oil to formulation could prevent droplets' growth caused by instability primary mechanism of nanoemulsions known as Ostwald ripening, which is characterized as the mass transfer from smaller to the larger oil droplets (Gupta et al., 2016; Helgeson, 2016). Furthermore, considering that there was no signal of instability for F1 and F5 formulations as well as this analysis at 3,618 rpm for $4.5 \mathrm{~h}$ corresponded to a predicted shelf life of 12 months, we could consider F1 and F5 NE as stable formulations for a such period of time. Accordingly, in view of all results described above, concerning NE formulation having the smallest oil droplets and narrow size distribution along with improved physical stability, we selected F1 formulation for further studies. Moreover, as expected the assessment of the incorporation efficiency of 1,8-cineole in $\mathrm{NE}$ formulation (F1) confirmed high entrapment $(86.3 \% \pm 0.87)$ into dispersed phase mainly due to limited water solubility of this monoterpene.

Table 3.

345 Distribution (D) of velocity $\left(\mu \mathrm{m} \mathrm{s}^{-1}\right)$ from droplet flotation of NE formulations measured at $25{ }^{\circ} \mathrm{C}$ using analytical photocentrifugation.

\begin{tabular}{lllll}
\hline NE & D10\% & D50\% & D90\% & Mean velocity \\
& $\left(\mu \mathrm{m} \mathrm{s}^{-1}\right)$ & $\left(\mu \mathrm{m} \mathrm{s}^{-1}\right)$ & $\left(\mu \mathrm{m} \mathrm{s}^{-1}\right)$ & $( \pm$ S.D. $)$ \\
\hline F1 & 1.280 & 1.619 & 2.290 & $1.634( \pm 0.377)$ \\
F2 & 1.605 & 89.190 & 260.551 & $4.462( \pm 104.703)$ \\
F3 & 1.510 & 3.106 & 199.099 & $3.140( \pm 82.126)$ \\
F4 & 1.820 & 168.326 & 268.696 & $8.540( \pm 94.195)$ \\
F5 & 1.291 & 1.641 & 2.279 & $1.645( \pm 0.364)$ \\
\hline
\end{tabular}



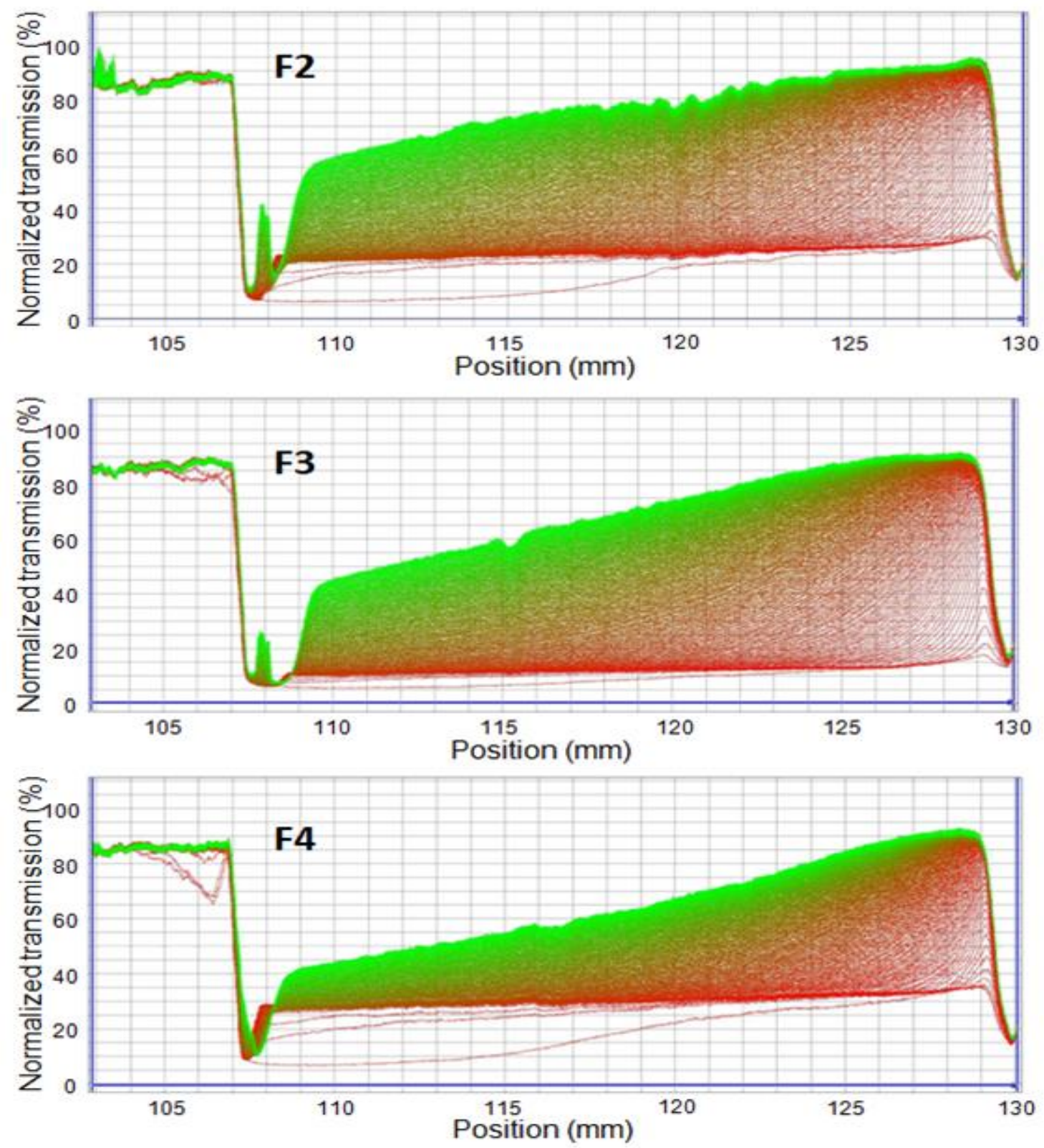

Fig. 2. Normalized NIR transmission profiles obtained with F2, F3, and F4 NE formulations by accelerated stability analysis during analytical centrifugation. The first

351 and the last registered profiles are shown in red and in green, respectively.

353 Transmission electron microscopy (TEM) has been considered a successful technique in order to analyze size and shape droplets, size distribution, and agglomeration tendency of the dispersed phase in nanoemulsified systems (Falsafi et al., 2020). TEM analyses were 
carried out for F1 formulation and images are depicted in Fig. 3. As can be noted from photomicrographs, throughout F1 formulation non-aggregated oil droplets with irregular spherical shapes were observed. Furthermore, oil droplet sizes viewed by TEM technique were similar to those measured by dynamic light scattering analysis. All these findings confirm the presence of nanosized oil droplets with uniform size distribution in the F1 formulation and its enhanced physical stability as previously related.
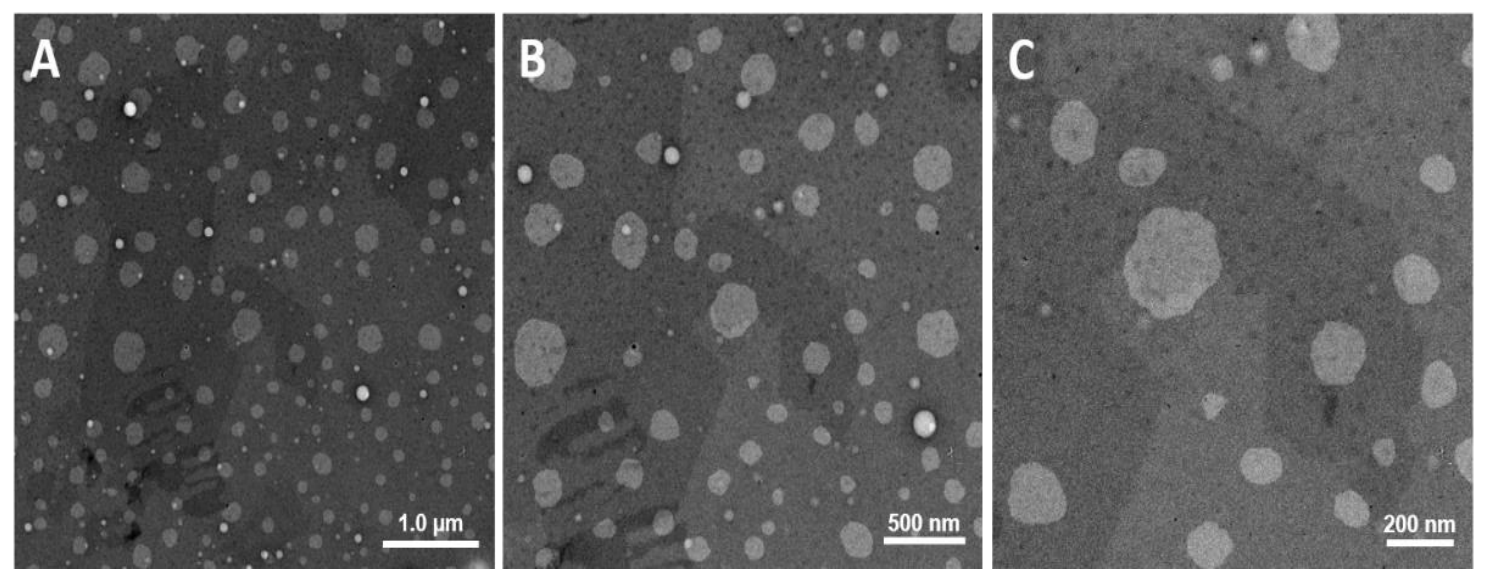

Fig. 3. TEM photomicrographs of cineole-containing NE (F1 formulation). Magnifications (A) x7.0K, (B) x12.0K, and (C) x20.0K.

The potential activity of free 1,8-cineole and cineole NE (F1 formulation) against Staphylococcus aureus, Enterococcus faecalis, and Streptococcus pyogenes strains was assessed using the broth microdilution method. As depicted in Table 4, the bactericidal concentrations of nanoemulsion containing 1,8-cineole were 2-fold lower than those found for free 1,8-cineole. More specifically, S. aureus and E. faecalis were more sensitive to the cineole NE when compared to free monoterpene, i.e., nanoemulsified cineole was the most effective in killing these two bacteria. Meanwhile, cineole nanoemulsion was only slightly more active against $S$. pyogenes in comparison with free cineole (Table 4). Both gentamicin $\left(1.66 \mathrm{mg} \mathrm{mL}^{-1}\right)$ and chlorhexidine digluconate $(1.2$ 

(F1 NE formulation) against Gram-positive bacteria.

\begin{tabular}{lll}
\hline Bacterial strains & Free cineole $\left(\mathrm{mg} \mathrm{mL}^{-1}\right)$ & Cineole-NE $\left(\mathrm{mg} \mathrm{mL}^{-1}\right)$ \\
\hline Staphylococcus aureus & 28.6 & 14.0 \\
Enterococcus faecalis & 28.6 & 14.0 \\
Streptococcus pyogenes & 28.6 & 24.0 \\
\hline
\end{tabular}

$\mathrm{mg} \mathrm{mL} \mathrm{m}^{-1}$ ) were found to be more active than pure cineole or cineole-NE against Grampositive bacteria.

Unlike these findings herein about free and nanoemulsified cineole against Gram-positive strains, Harkat-Madouri et al. (2015) found that the essential oil of Eucalyptus globulus, in which the major compound was 1,8-cineole, was more active against Gram-negative strains. Despite this, it is claimed that EO are relatively less active against Gram-negative than Gram-positive microorganisms due to the uppermost layer of lipopolysaccharide present on Gram-negative bacteria, thus limiting the diffusional process of lipophilic molecules (Harkat-Madouri et al., 2015; Prakash et al., 2018a). Furthermore, the enhanced antibacterial activity from nanoemulsified cineole could mainly be related to the increased surface area from ultra-small sized droplets in the nanoemulsion formulation allowing passive transport through the outer cell membrane (Prakash et al., 2018a).

\section{Table 4.}

Minimal bactericidal concentrations of free cineole and cineole-containing nanoemulsion
393

\section{Conclusions}

In summary, we have designed nanoemulsions containing 1,8-cineole using low energy emulsification, which is commonly known as spontaneous emulsification method. The 
most stable nanoemulsion formulation (F1) consisted mainly of very small sized droplets with monomodal size distribution, and negative zeta potential. Stability study demonstrated that F1 formulation could be considered stable with lower droplet migration velocity. In addition, high incorporation efficiency of 1,8-cineole into F1 formulation was demonstrated and also the photomicrographs from TEM analysis confirmed that F1 402 formulation was formed by nanosized droplets and no aggregation tendency. Antibacterial activity of cineole nanoemulsion against $S$. aureus and E. faecalis was enhanced (2-fold) compared to free 1,8-cineole. Hence nanoemulsified dispersions could be considered like a relevant lipid nanocarrier applied for inclusion of hydrophobic terpenic compounds. Moreover, these results encourage further studies about antibacterial activity of nanoemulsified cineole on preservation of food, cosmetic, and pharmaceutical products.

\section{Acknowledgments}

This study was supported by CAPES/COFECUB agreement (\#Ph-C 859-15).

\section{References}

414 Adak, T., Barik, N., Patil, N.B., Govindharaj, G.-P.-P., Gadratagi, B.G., Annamalai, M., Mukherjee, A.K., Rath, P.C., 2020. Nanoemulsion of eucalyptus oil: An alternative to synthetic pesticides against two major storage insects (Sitophilus oryzae (L.) and

417 Tribolium castaneum (Herbst)) of rice. Ind. Crop. Prod. 143, Article 111849. 418 https://doi.org/10.1016/j.indcrop.2019.111849.

419 Ali, B., Ali Al-Wabel, N., Shams, S., Ahamad, A., Alam Khan, S., Anwar, F., 2015. 420 Essential oils used in aromatherapy: A systemic review. Asian Pac. J. Trop. Biomed. 5, 
422 Anton, N., Vandamme, T.F., 2009. The universality of low-energy nano-emulsification. Int. J. Pharm. 377, 142-147. http://dx.doi.org/10.1016/j.ijpharm.2009.05.014. Anton, N., Vandamme, T.F., 2011. Nano-emulsions and Micro-emulsions: Clarifications of the Critical Differences. Pharm. Res. 28, 978-985. http://dx.doi.org/10.1007/s11095010-0309-1.

427 Asbahani, A.E., Miladi, K., Badri, W., Sala, M., Aït Addi, E.H., Casabianca, H., Mousadik, A.E., Hartmann, D., Jilale, A., Renaud, F.N.R., Elaissari, A., 2015. Essential oils: From extraction to encapsulation. Int. J. Pharm. 483, 220-243. http://dx.doi.org/10.1016/j.ijpharm.2014.12.069.

Bakkali, F., Averbeck, S., Averbeck, D., Idaomar, M., 2008. Biological effects of 432 essential oils - A review. Food Chem. Toxicol. 46, 446-475. 433 http://dx.doi.org/10.1016/j.fct.2007.09.106.

434 Bilia, A.R., Guccione, C., Isacchi, B., Righeschi, C., Firenzuoli, F., Bergonzi, M.C., 2014. 435 Essential Oils Loaded in Nanosystems: A Developing Strategy for a Successful 436 Therapeutic Approach. Evid.-Based Complementary Altern. Med. Article 651593. 437 http://dx.doi.org/10.1155/2014/651593.

438 CLSI, (2018). Clinical and Laboratory Standards Institute (CLSI). Methods for dilution 439 antimicrobial susceptibility tests for bacteria that grow aerobically. 11th ed. CLSI standard M07. Wayne, PA USA.

441 De Vincenzi, M., Silano, M., De Vincenzi, A., Maialetti, F., Scazzocchio, B., 2002. 442 Constituents of aromatic plants: eucalyptol. Fitoterapia 73, 269-275. 443 https://doi.org/10.1016/S0367-326X(02)00062-X.

444 Falsafi, S.R., Rostamabadi, H., Assadpour, E., Jafari, S.M., 2020. Morphology and 445 microstructural analysis of bioactive-loaded micro/ nanocarriers via microscopy 
techniques; CLSM/SEM/TEM/AFM. Adv. Colloid Interface Sci. 280, Article 102166.

447

448

449

450

451

452

453

454

455

456

457

458

459

460

461

462

463

464

465

466

467

468

469

470

\section{https://doi.org/10.1016/j.cis.2020.102166.}

Fernandes, A.R., Ferreira, N.R., Fangueiro, J.F., Santos, A.C., Veiga, F.J., Cabral, C., Silva, A.M., Souto, E.B., 2017. Ibuprofen nanocrystals developed by $2^{2}$ factorial design experiment: A new approach for poorly water-soluble drugs. Saudi Pharm. J. 25, 11171124. http://dx.doi.org/10.1016/j.jsps.2017.07.004.

Goto, P.L., Siqueira-Moura, M.P., Tedesco, A.C., 2017. Application of aluminum chloride phthalocyanine-loaded solid lipid nanoparticles for photodynamic inactivation of melanoma cells. Int. J. Pharm. 518, 228-241. https://doi.org/10.1016/j.ijpharm.2017.01.004.

Gupta, A., Eral, H.B., Hatton, T.A., Doyle, P.S., 2016. Nanoemulsions: formation, properties and applications. Soft Matter 12, 2826-2841.

\section{https://doi.org/10.1039/c5sm02958a.}

Hammoud, Z., Gharib, R., Fourmentin, S., Elaissari, A., Greige-Gerges, H., 2019. New findings on the incorporation of essential oil components into liposomes composed of lipoid S100 and cholesterol. Int. J. Pharm. 561, 161-170. https://doi.org/10.1016/j.ijpharm.2019.02.022.

Harkat-Madouri, L., Asma, B., Madani, K., Said, Z.B.-O.S., Rigou, P., Grenier, D., Allalou, H., Remini, H., Adjaoud, A., Boulekbache-Makhlouf, L., 2015. Chemical composition, antibacterial and antioxidant activities of essential oil of Eucalyptus globulus from Algeria. Ind. Crop. Prod. 78, 148-153. http://dx.doi.org/10.1016/j.indcrop.2015.10.015.

Harwansh, R.K., Deshmukh, R., Rahman, M.A., 2019. Nanoemulsion: Promising nanocarrier system for delivery of herbal bioactives. J. Drug. Deliv. Sci. Tec. 51, 224233. https://doi.org/10.1016/j.jddst.2019.03.006. 
471 Helgeson, M.E., 2016. Colloidal behavior of nanoemulsions: Interactions, structure, and

472 rheology. Curr. Opin. Colloid Interface Sci. 25, 39-50.

$473 \quad$ http://dx.doi.org/10.1016/j.cocis.2016.06.006.

474 Komaiko, J., McClements, D.J., 2015. Low-energy formation of edible nanoemulsions

475 by spontaneous emulsification: Factors influencing particle size. J. Food Eng. 146, 122-

476 128. http://dx.doi.org/10.1016/j.jfoodeng.2014.09.003.

477 Komaiko, J.S., McClements, D.J., 2016. Formation of Food-Grade Nanoemulsions Using

478 Low-Energy Preparation Methods: A Review of Available Methods. Compr. Rev. Food

479 Sci. Food Saf. 15, 331-352. https://doi.org/10.1111/1541-4337.12189.

480 Matos, S.P., Lucca, L.G., Koester, L.S., 2019. Essential oils in nanostructured systems:

481 Challenges in preparation and analytical methods. Talanta 195, 204-214. 482 https://doi.org/10.1016/j.talanta.2018.11.029.

483 McClements, D.J., Gumus, C.E., 2016. Natural emulsifiers - Biosurfactants, 484 phospholipids, biopolymers, and colloidal particles: Molecular and physicochemical 485 basis of functional performance. Adv. Colloid Interface Sci. 234, 3-26. 486 http://dx.doi.org/10.1016/j.cis.2016.03.002.

487 Prakash, A., Baskaran, R., Paramasivam, N., Vadivel, V., 2018a. Essential oil based 488 nanoemulsions to improve the microbial quality of minimally processed fruits and 489 vegetables: A review. Food Res. Int. 111, 509-523. 490 https://doi.org/10.1016/j.foodres.2018.05.066.

491 Prakash, B., Kujur, A., Yadav, A., Kumar, A., Singh, P.P., Dubey, N.K., $2018 b$.

492 Nanoencapsulation: An efficient technology to boost the antimicrobial potential of plant 493 essential oils in food system. Food Control 89, 1-11. 494 https://doi.org/10.1016/j.foodcont.2018.01.018. 
Rodrigues, F.V.S., Diniz, L.S., Sousa, R.M.G., Honorato, T.D., Simão, D.O., Araújo,

C.R.M., Gonçalves, T.M., Rolim, L.A., Goto, P.L., Tedesco, A.C., Siqueira-Moura, M.P.,

2018. Preparation and characterization of nanoemulsion containing a natural

498

499

500

501

502

503

504

505

506

507

508

509

510

511

512

513

514

515

516

517

518

519

naphthoquinone. Quim. Nova 41, 756-761. http://dx.doi.org/10.21577/0100-

\subsection{7.}

Saberi, A.H., Fang, Y., McClements, D.J., 2013. Fabrication of vitamin E-enriched nanoemulsions: Factors affecting particle size using spontaneous emulsification. J. Colloid Interface Sci. 391, 95-102. http://dx.doi.org/10.1016/j.jcis.2012.08.069.

Saberi, A.H., Fang, Y., McClements, D.J., 2014. Stabilization of vitamin E-enriched mini-emulsions: Influence of organic and aqueous phase compositions. Colloids Surf. A Physicochem. Eng. Asp. 449, 65-73. http://dx.doi.org/10.1016/j.colsurfa.2014.02.042.

Safaya, M., Rotliwala, Y.C., 2020. Nanoemulsions: A review on low energy formulation methods, characterization, applications and optimization technique. Mater. Today-Proc. 27, 454-459. https://doi.org/10.1016/j.matpr.2019.11.267.

Salehi, B., Sharifi-Rad, J., Quispe, C., Llaique, H., Villalobos, M., Smeriglio, A., Trombetta, D., Ezzat, S.M., Salem, M.A., Zayed, A., Castillo, C.M.S., Yazdi, S.E., Sen, S., Acharya, K., Sharopov, F., Martins, N., 2019. Insights into Eucalyptus genus chemical constituents, biological activities and health-promoting effects. Trends Food Sci. Technol. 91, 609-624. https://doi.org/10.1016/j.tifs.2019.08.003.

Singh, Y., Meher, J.G., Raval, K., Khan, F.A., Chaurasia, M., Jain, N.K., Chourasia, M.K., 2017. Nanoemulsion: Concepts, development and applications in drug delivery. J. Control. Release 252, 28-49. http://dx.doi.org/10.1016/j.jconrel.2017.03.008.

Slamenova, D., Horvathova, E., 2013. Cytotoxic, anti-carcinogenic and antioxidant properties of the most frequent plant volatiles. Neoplasma 60, 343-354. https://doi.org/10.4149/neo 2013046. 
520 Solans, C., Solé, I., 2012. Nano-emulsions: Formation by low-energy methods. Curr.

521 Opin. Colloid Interface Sci. 17, 246-254. https://doi.org/10.1016/j.cocis.2012.07.003.

522 Yin, H., Wang, C., Yue, J., Deng, Y., Jiao, S., Zhao, Y., Zhou, J., Cao, T., 2021.

523 Optimization and characterization of 1,8-cineole/hydroxypropyl- $\beta$-cyclodextrin inclusion 524 complex and study of its release kinetics. Food Hydrocoll. 110, 106159. $525 \quad$ https://doi.org/10.1016/j.foodhyd.2020.106159.

526 Zhao, T., Maniglio, D., Chen, J., Chen, B., Migliaresi, C., 2016. Development of pH527 sensitive self-nanoemulsifying drug delivery systems for acid-labile lipophilic drugs. 528 Chem. Phys. Lipids 196, 81-88. https://doi.org/10.1016/j.chemphyslip.2016.02.008. 